\title{
Formulation, Development and Evaluation of Meclozine Hydrochloride Microspheres
}

\section{Rasha M Kharshoum ${ }^{1}$ and Heba A Aboutaleb ${ }^{2 *}$}

${ }^{1}$ Department of Pharmaceutics, Bani-sueif University, Egypt

${ }^{2}$ Department of Pharmaceutics, Nahda University- Bani-sueif, Egypt

\begin{abstract}
Microspheres of meclozine hydrochloride $(\mathrm{MCZ} \mathrm{HCl})$ were formulated in order to prolong the residence time at the absorption site by intimate contact with the mucous membrane. The microspheres were prepared by orifaceionotropic gelation method using bioadhesive polymers such as xanthan, sodium, carboxy methyl cellulose ( $\mathrm{Na}$ CMC) and hydroxy propyl methylcellulose (HPMC k15) in combination with different ratio of sodium alginate. Totally nine different formulations of $\mathrm{MCZ} \mathrm{HCl}$ were prepared by using the above polymers. The microspheres were evaluated for percentage yield, entrapment efficiency, particle size analysis, surface morphology (scanning electron microscopy), differential scanning calorimetry $(D S C)$, swelling index, drug content and in-vitro dissolution study. The relative bioavailability of the optimized microspheres was compared with commercially available product after oral administration on healthy human volunteers using a randomized, cross-over design. The results revealed that mean particle sizes of the microspheres ranged from 565 to $649 \mu \mathrm{m}$ and the efficiency of entrapment ranged from $53.46 \%$ to $81.58 \%$. SEM photomicrograph showed microspheres with rough surface and spherical in shape. The DSC analysis revealed that the drug was uniformly distributed in the microspheres. The optimized microspheres exhibited a slow release over 8 hours. The pharmacokinetic data of the optimized microspheres formula showed prolonged $t_{\text {max }}$, and improved the relative bioavailability by $146.47 \%$ compared with commercially available tablets.
\end{abstract}

Keywords: Meclozine $\mathrm{HCl}$; Sodium alginate; Microspheres; Chitosan; Pharmacokinetics

\section{Introduction}

Meclozine hydrochloride $(\mathrm{MCZ} H \mathrm{HCl})$ is a first-generation antihistamine of the piperazine class drug that possesses anticholinergic and antispasmodic effect; it is often prescribed for vertigo, dizziness, motion sickness Meniere's disease, nausea and vomiting during pregnancy [4]. $\mathrm{MCZ} \mathrm{HCl}$ is practically insoluble in water, when administered orally, slow and incomplete absorption occurring from the gastrointestinal tract. Microspheres can control the delivery of drugs from days to months therefore reducing frequent administrations and improving patient compliance and comfort. Different release profiles with desired release rates can be achieved by selecting polymers with different degradation mechanisms [1]. Microspheres improve the bioavailability due to high surface to volume ratio and more contact time with mucous layer $[2,3]$. Use of natural and thus biodegradable polymers to achieve desired release profile is widely accepted practice in pharmaceutical formulation. In this experimental work, cellulose derivatives like chitosan and sodium alginate were used to prepare microspheres. Sodium alginate is used in combination with different polymers for sustained drug delivery of $\mathrm{MCZ} \mathrm{HCl}$. Sodium alginate $(S A)$ is a naturally occurring polysaccharide which can be easily crosslinked into a solid matrix by replacing the sodium ions from the guluronic acids with di- or tri-valent cations [5] and chitosan that has with excellent biodegradable and biocompatible characteristics [6,7].

The aim of this study is to develop novel $\mathrm{MCZ} \mathrm{HCl} \mathrm{microspheres}$ that sustained the release of $\mathrm{MCZ} \mathrm{HCl}$ and evaluate the effect of polymer type and the ratio of polymer to sodium alginate on drug release.

\section{Materials and Methods}

\section{Materials}

Meclozine hydrochloride, kindly supplied from Chemical Industries Development (CID) Co. (Cairo, Egypt). Sodium alginate with medium viscosity grade (1.05-1.15 $\mathrm{Pa}$ s) and hydroxyl propyl methylcellulose $\mathrm{k}_{15}$ were kindly provided by Pharco Group Pharmaceutical Co., Alexandria, Egypt. Xanthan gum and $\mathrm{Na}-\mathrm{CMC}$ were purchased from Sigma, USA. Isopropyl alcohol, calcium chloride from $A D W I C$, ElNasr Pharmaceutical Chemicals Co, Cairo, Egypt. Disodium hydrogen phosphate, potassium dihydrogen phosphate (E Merck, Darmstadt, Germany). All other ingredients were of analytical grade.

\section{Preparation of microspheres}

Aqueous solution of sodium alginate with xanthan gum, $\mathrm{Na}$-CMC and HPMC $k_{15}$ in the ratio of 1:1, 3:1, 5:1 were prepared as mentioned in Table 1 , fixed concentration of drug was dispersed in $1 \%$ chitosan solution then mixed with $(5 \% \mathrm{w} / \mathrm{v})$ calcium chloride solution in water. Polymers solution was dispersed drop wise using a syringe with a needle (0.9 $\mathrm{mm}$ diameter) into chitosan-calcium chloride solutions with continuous stirring using a magnetic stirrer (Jenway 1000, England) at $1000 \mathrm{rpm}$ for 10 minutes. Microspheres formed immediately and were left into the original solution for $24 \mathrm{hrs}$ to ensure internal gelation; they were filtered, washed with isopropyl alcohol and finally dried at $40^{\circ} \mathrm{C}$ in an incubator (Hereaus, Germany) for 24 hours [8-10].

\section{Characterization of the prepared microspheres}

Determination of percentage yield: The percentage yield of each

*Corresponding author: Heba A Aboutaleb, Department of Pharmaceutics, Nahda University- Bani-sueif, Egypt, Tel: +20 1003353631; E-mail: Habhob61076@yahoo.com

Received October 13, 2015; Accepted December 17, 2015; Published December 24, 2015

Citation: Kharshoum RM, Aboutaleb HA (2016) Formulation, Development and Evaluation of Meclozine Hydrochloride Microspheres. J Bioequiv Availab 8: 027032. doi: $10.4172 / \mathrm{jbb} .1000262$

Copyright: ( 2016 Kharshoum RM, et al. This is an open-access article distributed under the terms of the Creative Commons Attribution License, which permits unrestricted use, distribution, and reproduction in any medium, provided the original author and source are credited. 


\begin{tabular}{|c|c|c|c|c|}
\hline $\begin{array}{c}\text { Formulation } \\
\text { number }\end{array}$ & Polymer type & $\begin{array}{c}\text { SA : Polymer } \\
\text { ratio }\end{array}$ & Chitosan & $\begin{array}{c}\text { Cross linking agent } \\
\text { concentration } \\
\left(\mathbf{C a C L}_{\mathbf{2}} \mathbf{)}\right.\end{array}$ \\
\hline Formula 1 & Xanthan gum & $1: 1$ & $1 \%$ & $5 \%$ \\
\hline Formula 2 & Xanthan gum & $3: 1$ & $1 \%$ & $5 \%$ \\
\hline Formula 3 & Xanthan gum & $5: 1$ & $1 \%$ & $5 \%$ \\
\hline Formula 4 & Na-CMC & $1: 1$ & $1 \%$ & $5 \%$ \\
\hline Formula 5 & Na-CMC & $3: 1$ & $1 \%$ & $5 \%$ \\
\hline Formula 6 & Na-CMC & $5: 1$ & $1 \%$ & $5 \%$ \\
\hline Formula 7 & HPMC- $k_{15}$ & $1: 1$ & $1 \%$ & $5 \%$ \\
\hline Formula 8 & HPMC- $k_{15}$ & $3: 1$ & $1 \%$ & $5 \%$ \\
\hline Formula 9 & HPMC $-k_{15}$ & $5: 1$ & $1 \%$ & $5 \%$ \\
\hline
\end{tabular}

Table 1: Formulation of various batches for meclozine $\mathrm{HCl}$ microspheres.

batch was calculated in terms of percentage yield using the following equation [11].

$\%$ Yield $=($ practically obtained yield/theoretical yield $) \times 100$ (equation 1)

The practically obtained yield was determined by weighing all the formed microspheres, which were obtained by ionotropic gelation method, while the theoretical yield was determined by calculation assuming that the entire drug and polymer were used for microencapsulation and no loss occurs.

Determination of the entrapment efficiency: Weighed amounts of each microspheres formulation $(50 \mathrm{mg})$ was dissolved in methanol, sonicated for $10 \mathrm{~min}$ and the drug content was determined spectrophotometrically at $\lambda_{232} \mathrm{~nm}$. Entrapment efficiency of microspheres was calculated as follows:

Entrapment efficiency $=$ actual drug entrapped/theoretical drug content X100 (equation 2)

Particle size analysis: Particle size of microspheres were determined by using an optical microscope under regular polarized light, and the mean particle size was calculated by measuring 100 particles with the help of a calibrated ocular micrometer [12].

Surface morphology of microspheres: The surface morphology of the microspheres was examined by scanning electron microscope (Philips XL30, Netherlands) operated at 4-25 KV on samples goldsputtered for $120 \mathrm{~s}$ at $10 \mathrm{~mA}$, under argon at low pressure.

Thermal analysis using differential scanning calorimeter (DSC): The thermal properties of the drug, unloaded microspheres and loaded microspheres were examined using differential scanning calorimeter (Shimadzu DSC-50, Japan). The samples include pure $\mathrm{MCZ} \mathrm{HCl}$, physical mixture (drug, sodium alginate, and chitosan) and $\mathrm{MCZ} \mathrm{HCl}$ loaded alginate microspheres were placed in flat-bottomed aluminium pan and heated at a constant rate of $5^{\circ} \mathrm{C} / \mathrm{min}$, under nitrogen gas at a flow rate of $25 \mathrm{ml} / \mathrm{min}$. Data collection was carried out at a temperature range of $0-300^{\circ} \mathrm{C}$.

Swelling index (SI): The SI of the microspheres is an indication of the capacity of the microspheres to absorb water and swell. For estimating swelling index, $100 \mathrm{mg}$ of the microspheres were weighed then suspended in $\mathrm{HCl}$ ( $p H$ 1.2). After 10 hours microspheres were removed, surface water trapped with tissue paper and re-weighed $[13,14]$.

SI $=$ [weight of wet microspheres/weight of dry microspheres] $\mathrm{X} 100$ (equation 3)

Drug content: $10 \mathrm{mg}$ of the prepared microspheres were dissolved in $10 \mathrm{ml}$ methanol and the solutions were filtered and diluted then drug content was determined by UV spectrophotometer at $\lambda_{232} \mathrm{~nm}$. The drug concentration was calculated from the calibration curve.

In vitro dissolution study: The dissolution test was carried out using USP dissolution tester apparatus II (ERWEKA DT 700, Germany) in simulated gastric fluid of $\mathrm{pH} 1.2$ was used for $2 \mathrm{hrs}$ and phosphate buffer of $\mathrm{pH} 6.8$ for $6 \mathrm{hrs}$ as dissolution media. The paddles were rotated at a speed of $50 \mathrm{rpm}$. Capsules filled with amount of microspheres equivalent to $25 \mathrm{mg}$ of $\mathrm{MCZ} \mathrm{HCl}$ were placed in the cylinder and an aliquot of $5 \mathrm{ml}$ was collected at predetermined time intervals and replaced with fresh dissolution medium. The samples were filtered by passing through $0.45 \mu \mathrm{m}$ membrane filters (Millipore, USA) and analysed spectrophotometrically at $\lambda_{232} \mathrm{~nm}$. The experiments were done in triplicate.

\section{Pharmacokinetic study on human volunteers}

Study design and subjects: The study was carried out to compare the pharmacokinetics of $\mathrm{MCZ} \mathrm{HCl}$ from a microspheres formula ( $F 9$ ) to the marketed, conventional Dramamine $25 \mathrm{mg}$ tablet following the administration of a single dose of $M C Z H C L$, using two-way open-label randomized crossover study. The study was carried out on six healthy human volunteers (age: $20-40$ years; average weight: $75 \mathrm{~kg}$ and median height: $183 \mathrm{~cm}$ ). Health status of the volunteers was confirmed by laboratory analysis and physical examinations. Each volunteer signed an informed written consent and was fully informed with all the data concerning the drug. The study protocol was approved by research ethics committee, Faculty of Pharmacy, Banisueif University and the protocol complies with the declarations of Helsinki for humans. The drug was administered orally after overnight fasting and washout period of 1 week. The study was performed on two phases: phase I; all volunteers received Dramamine $25 \mathrm{mg}$ tablets, phase II; all volunteers received F9 microspheres which contain an amount equivalent to $25 \mathrm{mg} \mathrm{MCZ} \mathrm{HCl}$. Blood samples (5 ml) were collected after 0.5, 1, 2, $3,4,6,8,12$ and $24 \mathrm{hrs}$ after dose administration. All blood samples were instantly centrifuged at $3000 \mathrm{rpm}$ for $10 \mathrm{~min}$ (Hettich EBA 21 Centrifuge, Germany), and the plasma samples were frozen and stored at $-20^{\circ} \mathrm{C}$ till drug analysis. The volunteers' blood pressure, heart rate and adverse reactions were routinely monitored.

Mathematical modeling of $M C Z$ release: The release profiles of $M C Z$ from microspheres can be modeled mathematically to obtain information concerning the release mechanism. The release data obtained were fitted to different kinetic models: zero-order34, firstorder35, Higuchi36 and Korsmeyer-Peppas models [19] which are often used to describe the drug release behavior from the microspheres.

\section{Assay of MCZ HCL in human plasma}

Chromatographic conditions: The plasma concentration of $M C Z$ $\mathrm{HCl}$ was determined using a modified $H P L C-M S / M S$ method of Wang et al. [15] for the determination of $\mathrm{MCZ} \mathrm{HCl}$ in plasma. The HPLC apparatus consisted of isocratic pump LC-10 AS and a UV/VIS detector $S P D-10 A$ connected to a $C-R 6 A$ Integrator (Shimadzu, Koyoto, Japan). The analytical column was ponapak C18 HPLC column, $4.6 \times 250$ I.D mm, particle size $125^{\circ} \mathrm{A}$ (Waters Associates, Ireland). The mobile phase composed of acetonitrile and $0.2 \%$ formic acid containing $2 \mathrm{mM}$ amino acetate in a ratio $1: 1$. The mobile phase flow rate was $1 \mathrm{ml} / \mathrm{min}$. The system was operated at ambient temperature and the detection wavelength was $231 \mathrm{~nm}$.

Pharmacokinetic parameters and statistical analysis: The maximum drug concentration $\left(C_{\max }\right)$ and the corresponding time $\left(t_{\max }\right)$ 
Citation: Kharshoum RM, Aboutaleb HA (2016) Formulation, Development and Evaluation of Meclozine Hydrochloride Microspheres. J Bioequiv Availab 8: 027-032. doi:10.4172/jbb.1000262

were derived from the individual plasma concentration-time curves. The area under the curve was calculated by using WinNonlin (version 1.5 , Scientific consulting, Inc., Cary, NC, USA).

Pharmacokinetic characteristics from plasma data following administration of the two treatments were estimated for each subject using, WinNonlin: Non-compartmental analysis was used and the maximum drug concentration $\left(C_{\max }\right)$ and the corresponding time $\left(t_{\max }\right)$ were determined. The level of absorption from the microspheres formulation (F9) relative to the reference was calculated as the relative bioavailability by using the formula given below:

Relative bioavailability $(\%)=\left(\mathrm{AUC}_{0-24} / \mathrm{AUC}_{0-24}\right.$ reference $) 100 \mathrm{X}$.

\section{Results and Discussion}

\section{Micromeritic characterization of microspheres}

Micromeritic characterization of microspheres was determined by measuring the angle of repose, Carr's index and Hausner factor. The values of angle of repose were found between $\left(20^{\circ}\right.$ to $\left.31^{\circ}\right)$ which indicates optimum flow properties for filling into the capsules and all the batches of microspheres were found to fulfill with this in respect of flowability (Table 2) and thus it was possible to fill the microspheres into the capsules.

\section{Percentage yield}

Percentage yield of different formulations were calculated and the $\%$ yield was found between 65.26 and $84.63 \%$ (Table 3 ). The results indicated that sodium alginate: polymer (5:1) gives better percentage yield for $\mathrm{MCZ} \mathrm{HCl}$ microspheres than the other ratios 3:1, and 1:1. Also the formulations contain HPMC $K_{15}$ gave higher yield than that of xanthan gum, and the lowest yield was obtained from formulations containing $\mathrm{Na}-\mathrm{CMC}$.

\section{The entrapment efficiency}

The entrapment efficiency for the prepared formulation was in the range of 53.46-81.58\% (Table 3). The entrapment efficiency increased progressively with increasing the concentration of sodium alginate which could be attributed to the formation of larger microspheres that entrapped more amount of drug. This may be attributed to the greater availability of active calcium-binding sites in the polymeric chains and, consequently, the greater degree of cross-linking as the quantity of sodium alginate increased $[16,17]$. The incorporation efficiencies were also higher with the formulations containing $H P M C k_{15}$. The formulations containing $\mathrm{Na}$ - $\mathrm{CMC}$ had less amount of drug entrapment which may be due to the higher viscosity of $\mathrm{Na}-\mathrm{CMC}$.

\section{The particle size and surface morphology of the prepared microspheres}

The mean particle size of the different formulations of the prepared microspheres was between 565 and $692 \mu \mathrm{m}$ (Table 3), it was observed that the particle size increase with increasing in the concentration of sodium alginate ratio as shown in the formulations 3, 6 and 9 that contain the highest ratio of sodium alginate to polymer $(3: 1)$. This could be attributed to the increase in the relative viscosity at high concentration of the alginate and formation of large droplets during addition of the polymer solution to the gelling agents.

The SEM photomicrographs of the microspheres are shown in Figure 1, the morphology of the prepared microspheres was found to be almost spherical in shape and have rough surface.

\section{Differential scanning calorimetry}

The DSC thermograms of pure drug, unloaded alginate microspheres and drug loaded alginate microspheres are shown in Figure 2. $M C Z$ $\mathrm{HCl}$ exhibited a sharp endothermic peak at $206^{\circ} \mathrm{C}$ corresponding to its melting point. The peak of the drug in the physical mixture was observed that the large endothermic peak of pure drug was a bit smaller and shifted to $208.94^{\circ} \mathrm{C}$ in the physical mixture revealing its unchanged nature. This indicates no chemical or physical interaction between the drug and the polymer structure. The melting endotherm of $\mathrm{MCZ} \mathrm{HCl}$

\begin{tabular}{|c|c|c|c|c|c|}
\hline $\begin{array}{c}\text { Formulation } \\
\text { number }\end{array}$ & Bulk density & Tapped density & $\begin{array}{c}\text { Carr's index } \\
\text { (\%) }\end{array}$ & Hausner's factor & $\begin{array}{l}\text { Angle of repose } \\
\quad( \pm S . D)\end{array}$ \\
\hline Formula1 & 0.355 & 0.465 & 23.66 & 1.309 & $24.37 \pm 0.32$ \\
\hline Formula 2 & 0.387 & 0.491 & 21.18 & 1.268 & $23.99 \pm 0.19$ \\
\hline Formula 3 & 0.427 & 0.501 & 14.77 & 1.173 & $26.49 \pm 0.28$ \\
\hline Formula 4 & 0.361 & 0.472 & 23.52 & 1.307 & $28.53 \pm 0.25$ \\
\hline Formula 5 & 0.296 & 0.368 & 19.57 & 1.243 & $30.02 \pm 0.33$ \\
\hline Formula 6 & 0.311 & 0.372 & 16.40 & 1.196 & $31.32 \pm 0.26$ \\
\hline Formula 7 & 0.342 & 0.427 & 19.91 & 1.248 & $24.35 \pm 0.17$ \\
\hline Formula 8 & 0.325 & 0.396 & 17.93 & 1.218 & $22.38 \pm 0.20$ \\
\hline Formula 9 & 0.328 & 0.392 & 16.33 & 1.195 & $20.05 \pm 0.24$ \\
\hline
\end{tabular}

Table 2: Micrometrics characterization of various microspheres formulations.

\begin{tabular}{|c|c|c|c|c|}
\hline $\begin{array}{c}\text { Formulation } \\
\text { number }\end{array}$ & Yield value & Encapsulation efficiency (\%) & Swelling index (S) & $\begin{array}{c}\text { Drug content } \\
\mathbf{( \pm ~ S . D )}\end{array}$ \\
\hline Formula 1 & 69.84 & 67.96 & 1.42 & $99.45 \pm 5.16$ \\
\hline Formula 2 & 73.13 & 70.25 & 1.49 & $97.67 \pm 4.32$ \\
\hline Formula 3 & 79.79 & 74.66 & 1.54 & $100.3 \pm 3.84$ \\
\hline Formula 4 & 65.26 & 53.46 & 1.31 & $97.56 \pm 4.99$ \\
\hline Formula 5 & 68.67 & 58.60 & 1.37 & $99.45 \pm 4.87$ \\
\hline Formula 6 & 72.05 & 58.46 & 1.40 & $97.67 \pm 2.94$ \\
\hline Formula 7 & 74.32 & 61.38 & 1.44 & 64.16 \\
\hline Formula 8 & 80.38 & 75.63 & 1.55 & 98.19 \\
\hline Formula 9 & 84.36 & 81.58 & 1.62 & $99.28 \pm 5.11$ \\
\hline
\end{tabular}

Table 3: Physicochemical characterization of various microspheres formulations. 
Citation: Kharshoum RM, Aboutaleb HA (2016) Formulation, Development and Evaluation of Meclozine Hydrochloride Microspheres. J Bioequiv Availab 8: 027-032. doi:10.4172/jbb.1000262

\begin{tabular}{|c|c|c|c|c|c|}
\hline Formulation & Zero order & First order & Higushi & Peppas equation & $\begin{array}{c}\text { (n) Values peppas } \\
\text { equation }\end{array}$ \\
\hline Formula1 & 0.883 & 0.961 & 0.992 & 0.981 & 0.472 \\
\hline Formula 2 & 0.891 & 0.934 & 0.985 & 0.974 & 0.463 \\
\hline Formula 3 & 0.912 & 0.927 & 0.988 & 0.967 & 0.452 \\
\hline Formula 4 & 0.935 & 0.945 & 0.993 & 0.985 & 0.472 \\
\hline Formula 5 & 0.902 & 0.947 & 0.979 & 0.977 & 0.483 \\
\hline Formula 6 & 0.969 & 0.955 & 0.981 & 0.969 & 0.491 \\
\hline Formula 7 & 0.954 & 0.972 & 0.993 & 0.881 & 0.484 \\
\hline Formula 8 & 0.911 & 0.962 & 0.962 & 0.891 & 0.492 \\
\hline Formula 9 & 0.965 & 0.942 & 0.982 & 0.965 & 0.40 \\
\hline
\end{tabular}

Table 4: Correlation coefficient $\left(R^{2}\right)$ values of various kinetic models used for analysis of the release data of Meclozine $\mathrm{HCl}$ microspheres and $(n)$ values in Peppas Equation
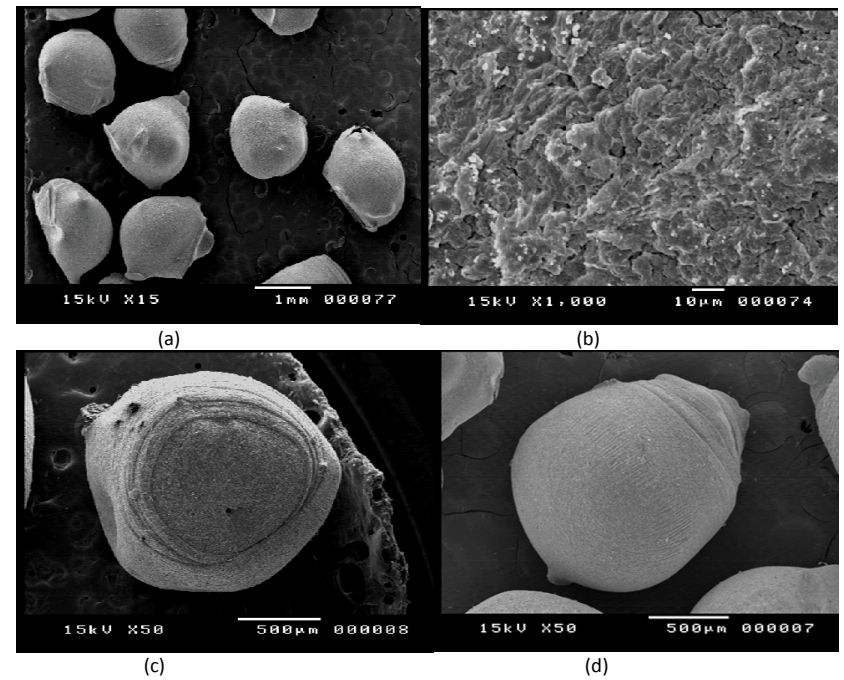

Figure 1: Scanning electron photomicrographs of the optimized formula of microspheres (F9) at different magnifications.

(a)
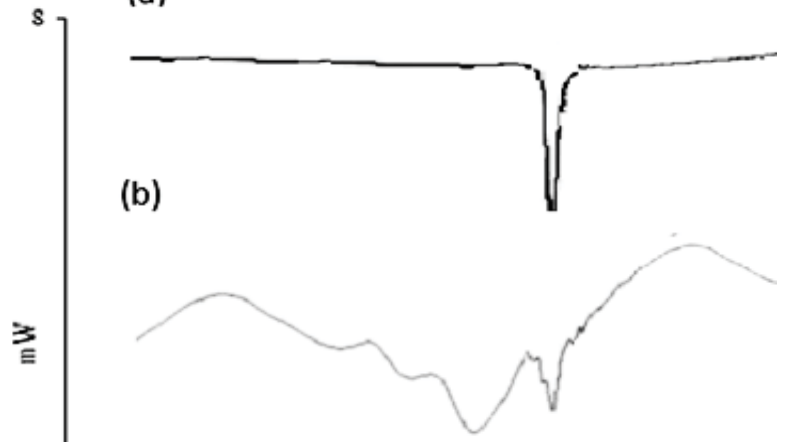

(c)

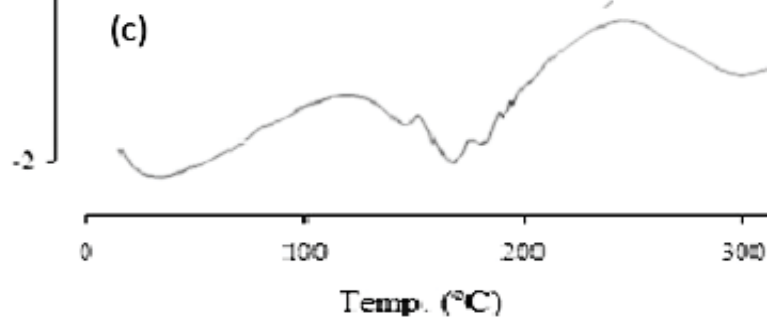

Figure 2: $D S C$ thermograms of: a) pure $\mathrm{MCZ} \mathrm{HCl}$; b) Physical mixture; C) Drug loaded microspheres was not observed in the drug loaded microspheres which indicates that $\mathrm{MCZ} \mathrm{HCl}$ was uniformly dispersed and present in an amorphous state in the polymeric matrix [18-23].

\section{Swelling study}

It was found that by the increasing of alginate concentration the swelling index increase this was due to the high absorption capacity of alginate. All microspheres began to swells presumably due to an increase in the electrostatic repulsive forces at a $p H$ above the $p K_{a}$ of the uronic acid groups on the alginate [18]. Also swelling of the dry microspheres can be attributed to the hydration of the hydrophilic groups of alginate and chitosan. In this case free water penetrates inside the microspheres in order to fill the pores among polymer chains, contributing to a greater swelling degree [18].

\section{In-Vitro drug release}

It is observed from the cumulative drug release profile (Figure 3) that the more sustained effect occurs with the increase in the concentration of sodium alginate which may attributed to the formation of larger microspheres which in turn increase the diffusional path length that delayed the rate of drug release. F9 containing $5 \% \mathrm{w} / \mathrm{v}$ sodium alginate with HPMC $\mathrm{k}_{15}$, showed controlled release patterns of drug, the release was $82.45 \%$ after 8 hours indicating the appropriate choice of the formulation variables.

\section{In-Vitro drug dissolution kinetics}

For understanding the mechanism of drug release the in-vitro drug dissolution data obtained was fitted to various mathematical models such as zero order, First order, Higuchi and Krosmeyer-Peppas model.

The kinetic data were analysed of all the formulations and the coefficient of determination $\left(R^{2}\right)$ was used as an indicator of the best fitting for each model. From Table 4 it was seen that the highest correlation coefficient $\left(R^{2}\right)$ was obtained for Higuchi model, this indicates that release of drug from prepared microspheres formulation followed diffusion mechanism [20,21]. Also, kinetic treatment results revealed that the $n$ values were less than 0.5 for the same formulae that confirmed Fickian diffusion mechanism for the release of $M C Z$ from the prepared microspheres [22].

\section{Pharmacokinetic study in human volunteers}

F9 was selected for the Pharmacokinetic study according to the micromeritcs results, physicochemical characterization and in vitro results. The mean plasma concentration-time data of $\mathrm{MCZ} \mathrm{HCl}$ following the administration of the marketed Dramamine $25 \mathrm{mg}$ tablet and formula (F9) is shown in Figure 4. The pharmacokinetic results are shown in Table 5, against marketed Dramamine $25 \mathrm{mg}$ tablet the study revealed that the administration of $\mathrm{MCZ} \mathrm{HCl}$ as microspheres 
Citation: Kharshoum RM, Aboutaleb HA (2016) Formulation, Development and Evaluation of Meclozine Hydrochloride Microspheres. J Bioequiv Availab 8: 027-032. doi:10.4172/jbb.1000262

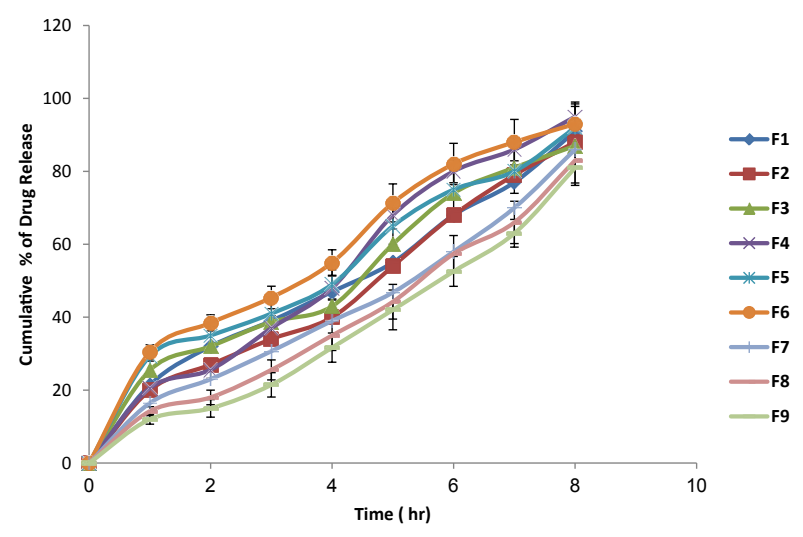

Figure 3: Dissolution Profile of Meclozine Hydrochloride from the prepared microspheres

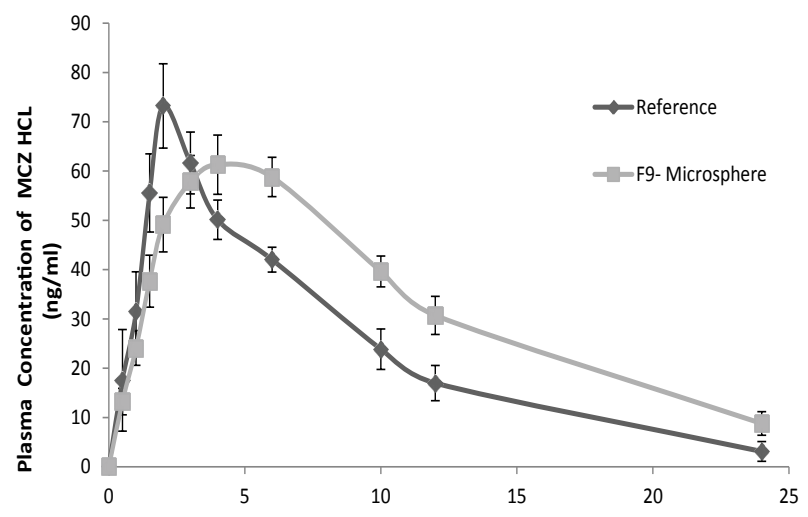

Figure 4: Plasma concentration of $M C Z H C L$ following the administration of the commercially available product and the prepared microspheres $(F 9)$, data represent the mean values of $n=6 \pm S$.D.

\begin{tabular}{|c|c|c|}
\hline \multirow[t]{2}{*}{ Pharmacokinetic parameter } & \multicolumn{2}{|c|}{ Formula } \\
\hline & $\begin{array}{c}\text { commercially } \\
\text { available product } \\
\text { product }\end{array}$ & F9 microspheres \\
\hline$C p_{\max }(n g / m l)$ & $70.34 \pm 2.265$ & $61.29 \pm 6.01$ \\
\hline$t_{\max }(h r)$ & $2.17 \pm 0.48$ & $4.66 \pm 0.94$ \\
\hline$A \cup C_{(0-24)}(n g \cdot h r / m l)$ & $572.37 \pm 68.34$ & $787.25 \pm 89.14$ \\
\hline$A \cup C_{(0-\alpha)}(n g \cdot h r / m l)$ & $594.3509 \pm 73.14$ & $870.2867 \pm 97.23$ \\
\hline$\%$ Relative Bioavailability & - & $1.465 \%$ \\
\hline${ }^{*} t_{1 / 2}(h r)$ & $4.8833 \pm 0.51$ & $6.5438 \pm 0.64$ \\
\hline$M R T(h r)$ & $7.7589 \pm 1.13$ & $10.9479 \pm 1.14$ \\
\hline
\end{tabular}

Table 5: Mean pharmacokinetic parameters of $\mathrm{MCZ} \mathrm{HCl}$ following the oral administration of a single dose $(25 \mathrm{mg})$ of the commercially available product and the prepared microspheres.

can improve the relative bioavailability compared to the marketed oral tablet. The $t_{\max }$ of $\mathrm{MCZ} \mathrm{HCl} \mathrm{microspheres} \mathrm{were} 4.66 \pm 0.94 \mathrm{~h}$ which is significantly higher than the conventional tablets $2.17 \pm 0.48 \mathrm{~h}$. This can be attributed to the retardation of the absorption through increase the contact time at the absorption site and increase the mean resident time (MRT) of the drug. The increase in the mean $t_{\max }$ and the decrease in the mean $C_{\max }$ compared with the marketed tablet confirmed controlled-release effect of the microspheres formulations. The mean $A U C_{0-24}$ was found to be $787.25 \pm 89.14 \mathrm{ng} \mathrm{h} / \mathrm{ml}$ for F9 compared with $572.37 \pm 68.34 \mathrm{ng} \mathrm{h} / \mathrm{ml}$ for marketed tablets. From these results, it was found that, the relative bioavailability of $\mathrm{MCZ} \mathrm{HCl}$ from the optimized formula was $146.5 \%$ compared to marketed tablets, which may be due to the increasing in the contact time with the gastric mucosa by the polymers, lead to prolongation in the gastric empting rate that led to a longer absorption and improving the bioavailability.

\section{Conclusion}

The above observations suggested that the $\mathrm{MCZ} \mathrm{HCl}$ can be developed as drug delivery system with sodium alginate and HPMC $k_{15}$ using calcium chloride as cross linking agent and $1 \%$ chitosan as polymer. The microspheres used as drug delivery system for $M C Z$ $\mathrm{HCl}$ was successfully prepared by inotropic gelation method and it was found to be a promising formula in the development of a novel sustained drug delivery that help to reduce the dose of the drug and improve its bioavailability.

\section{References}

1. Wood CD, Cramer DB, Graybiel A (1981) Antimotion sickness drug efficacy Otolaryngol Head Neck Surg 89: 1041-1044.

2. Smart JD (2005) The basics and underlying mechanisms of mucoadhesion Adv Drug Deliv Rev 57: 1556-1568.

3. Aulton ME (2002) Pharmaceutics: The science of dosage form design, $2^{\text {nd }}$ (Edn), Churchill Livingston, New York 197-210.

4. Henriksen L, Green KL, Smart JD, Smistad G, Karlsen J (1996) Bioadhision of hydrated chitosan: An invitro and invivo study. Int J Pharm 145: 231-241

5. George M, Abraham TE (2006) Polyionic hydrocolloids for the intestinal delivery of protein drugs: alginate and chitosan--a review. J Control Release 114: 1-14.

6. Alaa EBY, Ibrahim A, Alsarra AMA (2006) Chitosan beads as a new gastroretentive system of Verapamil. Sci Pharm 74: 175-188.

7. Cai D, Zeng C, Quan D, Bu L, Wang K, et al. (2007) Biodegradable chitosan scaffold containing microspheres as carriers for controlled transforming growth factor-ß1 delivery for cartilage tissue engineering. Ch Med J 120: 197-203.

8. Wan LS, Heng PW, Chan LW (1992) Drug encapsulation in alginate microspheres by emulsification. J Microencapsul 9: 309-316.

9. Anwar M, Warsi MH, Mallick N, Akhter S, Gahoi S, et al. (2011) Enhanced bioavailability of nano-sized chitosan-atorvastatin conjugate after oral administration to rats. Eur J Pharm Sci 44: 241-249.

10. Chretien C, Boudy V, Allain P, Chaumeil JC (2004) Indomethacin release from ion-exchange microspheres: impregnation with alginate reduces release rate. $J$ Control Release 96: 369-378.

11. Martin A, Bustamante P, Chun AHC (1993) Micromeritics. In: Mundorff GH (Eds) Physical pharmacy; Physical and chemical principles of pharmaceutical science. $4^{\text {th }}($ Edn) Philadelphia (PA): Lippincott Williams \& Wilkins 423-452.

12. Ansel HC, Allen LV, Popvich JNG (1999) Pharmaceutical dosage forms and drug delivery systems, $7^{\text {th }}(E d n)$ Phildelphia: Lippincott Williams and Wilkins 164-178.

13. Anwar M, Warsi MH, Mallick N, Akhter S, Gahoi S, et al. (2011) Enhanced bioavailability of nano-sized chitosan-atorvastatin conjugate after oral administration to rats. Eur J Pharm Sci 44: 241-249.

14. Dandagi PM, Mastiholimath VS, Gadad AP, Iliger SR (2007) microspheres of propranolol hydrochloride for nasal delivery. Indian J Pharm Sci 69: 402-407

15. Wang Z, Qian S, Zhang Q, Chow MS (2011) Quantification of meclizine in human plasma by high performance liquid chromatography-mass spectrometry. J Chromatogr B Analyt Technol Biomed Life Sci 879: 95-99.

16. El-Kamel AH, Al-Gohary OM, Hosny EA (2003) Alginate-diltiazem hydrochloride beads: optimization of formulation factors, in vitro and in vivo availability. J Microencapsul 20: 211-225. 
Citation: Kharshoum RM, Aboutaleb HA (2016) Formulation, Development and Evaluation of Meclozine Hydrochloride Microspheres. J Bioequiv Availab 8: 027-032. doi:10.4172/jbb.1000262

17. Das MK, Senapati PC (2008) Furosemide-loaded Alginate Microspheres Prepared by lonic Cross-linking Technique: Morphology and Release Characteristics. Indian J Pharm Sci 70: 77-84

18. Manjanna KM, Shivakumar B, Pramodkumar TM (2009) Formulation of ora sustained release aceclofenac sodium microspheres. Int J PharmTech Res 1: 940-952.

19. Korsmeyer RW, Gurny R, Doelker E, Buri P, Peppas NA (1983) Mechanisms of solute release from porous hydroliphic polymers. Int J Pharm 15: 25-35.

20. Polli JE, Rekhi GS, Augsburger LL, Shah VP (1997) Methods to compare dissolution profiles and a rationale for wide dissolution specifications for metoprolol tartrate tablets. J Pharm Sci 86: 690-700.
21. Wu PC, Tsai MJ, Huang YB, Chang JS, Tsai YH (2002) In vitro and in vivo evaluation of potassium chloride sustained release formulation prepared with saturated polyglycolyed glycerides matrices. Int J Pharm 243: 119-124.

22. Ritger PL, Peppas NA (1987) A simple equation for description of solute release II. Fickian and anomalous release from swellable devices. J Control Release 5: 37-42.

23. Senthil K, Avik KS, Kunchu K, Sanat KB (2012) Evaluation of clobazam loaded ionically cross-linked microspheres using chitosan. Der Pharmacia Sinica 3 : 616-623. 